\title{
Is Sleep a Commodity to Trade-Off for Generation Z?
}

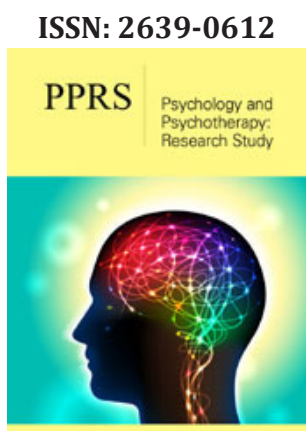

*Corresponding author: Amrit Kumar Jha, Department of Psychology, C. M. College, Lalit Narayan Mithila University, Darbhanga, Bihar, 846004, India, India

Submission: 眥 March 10, 2020

Published: 留June 18, 2020

Volume 3 - Issue 5

How to cite this article: Amrit Kumar Jha. Is Sleep a Commodity to Trade-Off? Psychol Psychother Res Stud. 3(5). PPRS. 000572. 2020

DOI: 10.31031/PPRS.2020.03.000572

Copyright@ Amrit Kumar Jha, This article is distributed under the terms of the Creative Commons Attribution 4.0 International License, which permits unrestricted use and redistribution provided that the original author and source are credited.

\author{
Amrit Kumar Jha* \\ Department of Psychology, India
}

\begin{abstract}
The purpose of the paper is to throw light on the depreciating level of sleep and the repercussion among the present youths, popularly known as Gen $\mathrm{Z}$ or the iGens. The mini review intends to bring the past researches exploring youth's attitude toward sleep and understanding the factors that promote sleep deprivation. It was found that cultural, technological, and social factors are the potent reasons behind their sleep deprivation. Given the burgeoning size of youth and their indispensability, it is felt that the sleep-wake cycle and mindset toward sleep need to be corrected at the earliest.
\end{abstract}

Keywords: Sleep; Youth; Generation Z; Culture; Chronotype; Sleep deprivation

\section{Is Sleep a Commodity to Trade-Off?}

Mr. $X$ is an undergrad student of Psychology major. He works as a part timer in an online sales company post-college hour. After finishing his class in the afternoon, he joins his duty and works till 9-10PM in the night, sometimes extending into midnight. Post-dinner, after hitting the bed, he is glued to his mobile and laptop, checking the mails, enjoying the pleasantries through chatting and video calling his friends on Whats app, uploading pictures on Facebook and Instagram, forcing him to sleep late, only to wake early in the morning to live his life in the fixed sleep-wake routine.

The aforementioned case represents the present lifestyle of todays' youth. UN defined youths in the age category of 15-23 years. Going by this definition in present time, the eldest youth of today was born in 1997 and the youngest in 2005. In generational study, people born in this year range are labeled as Generation- Z or the netizens or the iGens [1]. Together with their immediate predecessors, millennials (born between 1981-1996), they constitute about $63 \%$ of the world population. Recognized as ambitious, achievers, innovators, tech-savvy, on one hand and narcissist, impulsive, impatient on the other [1], they are already influencing the globe at present, courtesy the rise of start-ups and unicorns. Continuing this trend, they will have massive role in defining the future. However, their existing picture seems gloomy, as they are found out to be the most stressed out generation in the present-day world and second most vulnerable to suicide [2]. The story does not end here as they are ignoring the most vital day-to-day activity of their life by sleeping less and following a trend which invites multiple psychological, physiological, cardiovascular, and even financial concerns in time to come, which they are totally oblivious of.

Sleep is food for the brain and carries an evolutionary survival value for the mankind. It is one of those activities that all the living organism including the homo sapiens imbibed since ages. The sleep pattern of human beings is different compared to their animal counterparts with less amount of sleep and more efficiency, reflecting our more evolved sleep across the phylogeny class [3]. Even in such an evolved shorter span of time devoted to sleep, today's youth trade their sleep time with other priorities of life, making the already shorter sleepwake cycle, shortest!

Extant studies have documented the numerous benefits of sleep [4]. The irony lies here is in spite of the shared understanding related to the importance of sleep, Generation $\mathrm{Z}$ consciously devote it less time, which gradually turn into a habit, making it a practice. 
Numerous factors propel such casual approach toward sleep. In one of our study in India, we found that both the cultural and modern industrialized world advancements and practices has contributed immeasurably toward youth's sleep deprivation [5].

Devoting time to sleep is considered a waste of time and sign of a lazy, incompetent, and unproductive person and has been culturally ingrained over the years. Furthermore, the incessant use of technological devices at night adds fuel to the fire. Studies have observed the usage impede production of melatonin hormone (responsible for sleep) by 85\% courtesy light emitting diode [6]. Besides, the presence of artificial lights round the clock, preference toward desk jobs, sedentary lifestyle, change in nature of workplace viz. work from home, flexi-work, work in shifts, weaken the social zeitgeber (german word for time giver or cues) regulating the sleepwake cycle.

To make the matter worst, the growing competition and persistent pressure on and off the academic institute to perform well across the exams in order to meet parental (and significant others') expectations further compel the youths to stay awake, study more, and complete assignments/projects on the cost of sacrificing the sleep. Studies in chronobiology has revealed that most human beings in this age of life turn into evening types, posing further problems for the youth to attend morning classes and hence sleep deprivation [7].

What is alarming here is the established belief that if one sleep less, she/he gains and if she/he sleep more, she/he losses.
Substituting sleep timing with waking hours is perceived as tangible productivity, which in real sense, can only be derived by sleeping well [8]. The growing sedentary lifestyle, bombarding of excessive electric lights round the clock, less physical activities, more indoor hours, unregulated use of sleep-eroding technological devices, and to top it all, a casual and demeaning mindset for sleep set a catastrophic tone for the youths in the future to come.

\section{References}

1. Twenge JM, Krizan Z, Hisler G (2017) Decreases in self-reported sleep duration among US adolescents 2009-2015 and association with new media screen time. Sleep Med 39: 47-53.

2. American Psychological Association (2014) Stress in America TM: Are teens adopting adults' stress habits?

3. Samson DR, Nunn CL (2015) Sleep intensity and the evolution of human cognition. Evol Anthropol 24(6): 225-237.

4. Imeri L, Opp MR (2009) How (and why) the immune system makes us sleep. Nature Reviews Neuroscience 10(3): 199-210.

5. Jha AK, Pandey V, Kumari V (2019) What's eating up adolescent sleep: Evidence from Bihar. Gujarat Research Society 21(9).

6. Gooley JJ, Chamberlain K, Smith KA, Khalsa SBS, Rajaratnam SM, et al. (2010) Exposure to room light before bedtime suppresses melatonin onset and shortens melatonin duration in humans. J Clin Endocrinol Metab 96(3): 463-472.

7. Roenneberg T (2012) Internal time: Chronotypes, social jet lag, and why you're so tired. Harvard University Press, USA.

8. Stillman D, Stillman J (2017) Gen Z Work: How the Next Generation Is Transforming the Workplace. HarperCollins, USA. 